\title{
DESENVOLVIMENTO E VALIDAÇÃO DE UM MÉTODO ANALÍTICO SIMPLES E RÁPIDO POR ESPECTROSCOPIA UV PARA QUANTIFICAÇÃO DE ACICLOVIR EM MATRIZES HIDROFÍLICAS DE LIBERAÇÃO PROLONGADA
}

Fernanda Malaquias Barboza, Débora Dalla Vecchia, Airton Vicente Pereira e Hellen Karine Stulzer*

Departamento de Ciências Farmacêuticas, Universidade Estadual de Ponta Grossa, 84010-919 Ponta Grossa - PR, Brasil

Marcos Antonio Segatto Silva

Departamento de Ciências Farmacêuticas, Universidade Federal de Santa Catarina, 88040-900 Florianópolis - SC, Brasil

Recebido em 8/7/09; aceito em 11/9/09; publicado na web em 24/2/10

\begin{abstract}
DEVELOPMENT AND VALIDATION OF A SIMPLE AND RAPID ANALYTICAL METHOD BY UV SPECTROSCOPY FOR ACYCLOVIR QUANTIFICATION IN HYDROPHILIC MATRICES FOR SUSTAINED RELEASE. This work reports the validation of an analytical UV spectrophotometric method to assay acyclovir in hydrophilic matrices (assay and dissolution studies). The method was linear in the range between $2.5-20 \mu \mathrm{g} \mathrm{mL}-1$, presenting a good correlation coefficient $(\mathrm{r}=0,9999)$. Precision and accuracy analysis showed low relative standart deviation $(<2.0 \%)$ and a good recoveries percentual (98.9-100 \%). The procedure was linear, accurate, and robust. The method is simple and cheap. It does not use polluting reagents and can be applied in dissolution studies, being an adequate alternative to assay acyclovir in hydrophilic matrices tablets.
\end{abstract}

Keywords: acyclovir; hydrophilic matrices; UV spectrophotometry.

\section{INTRODUÇÃO}

O aciclovir (ACV), um análogo sintético da 2'-desoxiguanosina, é o mais efetivo e seletivo agente contra os vírus do grupo da herpes existente na atualidade, é considerado o tratamento de escolha para as infecções causadas pelo HSV, devido à sua alta seletividade pelo vírus herpético e baixa citotoxidade às células do hospedeiro, sendo particularmente ativo contra herpes labial e genital. ${ }^{1,2}$<smiles>Nc1nc2c(ncn2COCCO)c(=O)[nH]1</smiles>

Figura 1. Estrutura química do aciclovir

A absorção limitada por via oral de fármacos como o aciclovir, cujo tempo de meia-vida biológica é curto e a hidrossolubilidade é baixa, ${ }^{3}$ estimulam o desenvolvimento de sistemas de liberação modificada desses ativos, como sistemas matriciais. ${ }^{4,5}$

A importância terapêutica do ACV vem sendo demonstrada pelo desenvolvimento de diferentes formulações e métodos de quantificação. A literatura descreve alguns métodos para quantificação desse antiviral, como matéria-prima ou em formulações farmacêuticas convencionais, baseados em diferentes técnicas analíticas. Entre as distintas técnicas, citam-se espectrofotometria simples na região do visível com reação colorimétrica em meio básico, espectrofotometria UV para quantificação em comprimidos convencionais, espectrofluorometria, eletroquimiluminescência em célula galvânica e cromatografia líquida de alta eficiência (CLAE) com detector UV, sendo este último também o método descrito pela farmacopeia americana. ${ }^{6-12}$

Entre os diferentes métodos descritos, a espectrofotometria na região UV do espectro eletromagnético é um dos métodos analíticos mais empregados, em função de robustez e custo relativamente baixo. ${ }^{13}$

*e-mail: hellen.stulzer@gmail.com
O controle de qualidade tornou-se uma ferramenta imprescindível para a indústria farmacêutica, pois a partir dele pode-se garantir um medicamento seguro e eficaz. A confiabilidade dos resultados do controle de qualidade de medicamentos é alcançada através da validação dos métodos analíticos. ${ }^{14}$

Os estudos de dissolução são indispensáveis nas etapas de desenvolvimento de formulações, na identificação de variáveis críticas, na produção e controle de qualidade de medicamentos, bem como permitem estabelecer as correlações in vivo/in vitro. ${ }^{15}$

A literatura consultada não apresenta metodologia analítica para a quantificação de ACV em matrizes hidrofílicas; considerando o exposto, para o controle de qualidade rotineiro, o desenvolvimento de um método simples, rápido e sensível é altamente desejável. Assim, procedeu-se o desenvolvimento e validação de uma metodologia analítica que englobasse estas características para quantificação do aciclovir nas matrizes hidrofílicas desenvolvidas, aplicando-o para os ensaios de dissolução.

\section{PARTE EXPERIMENTAL}

\section{Materiais e equipamentos}

O fármaco aciclovir foi cedido pela empresa Eurofarma, este proveniente do fornecedor Chemo SA, número de lote 4507062001. O padrão de aciclovir é proveniente da Farmacopeia Brasileira. As amostras foram analisadas usando-se espectrofotômetro UV (Genesys 10S) em $254 \mathrm{~nm}$.

\section{Preparo da solução padrão}

A solução padrão foi preparada dissolvendo-se $10 \mathrm{mg}$ de padrão de aciclovir, precisamente pesado, em uma solução de $\mathrm{HCl} 0,1 \mathrm{~N}$, em balão volumétrico de $100 \mathrm{~mL}$. A partir dessa solução foram preparadas as amostras com diferentes concentrações.

\section{Preparo das amostras}

Dez comprimidos matriciais contendo $200 \mathrm{mg}$ de ACV foram 
pesados e triturados. Uma quantidade equivalente a $10 \mathrm{mg}$ de fármaco foi pesada. As soluções foram preparadas dissolvendo-se esse conteúdo em solução de $\mathrm{HCl}$ 0,1 N e completando-se o volume, com a mesma solução, em balão volumétrico de $100 \mathrm{~mL}$.

\section{Validação da metodologia analítica}

O método foi validado conforme o preconizado na Resolução RE $n^{\circ} 899$, de 29/5/2003 e com as recomendações da ICH (The International Conference on Harmonisation of Technical Requirements for Registration of Pharmaceuticals for Human Use). ${ }^{16,17}$ Os parâmetros avaliados foram especificidade, linearidade e faixa, limites de quantificação (LQ) e detecção (LD), precisão, exatidão e robustez.

\section{Especificidade}

A especificidade do método foi avaliada através de análises comparativas entre as formulações sem aciclovir (placebo) e as contendo o aciclovir.

\section{Linearidade e faixa}

Foram verificadas através da construção de uma curva de calibração em triplicata, contemplando concentrações de 2,5; 5; 10; 15 e $20 \mu \mathrm{g} \mathrm{mL}^{-1}$. A equação da reta foi determinada através do estudo de regressão linear.

Limites de quantificação $(L Q)$ e detecção $(L D)$

Foram calculados a partir do desvio padrão da resposta $(\sigma)$ e coeficiente angular (s), através das Equações 1 e 2:

$$
\begin{aligned}
& L Q=\left(\frac{10 \sigma}{S}\right) \\
& L D=\left(\frac{3.3 \sigma}{S}\right)
\end{aligned}
$$

\section{Precisão}

A precisão intercorrida (repetibilidade) foi avaliada através da análise de seis soluções amostra na concentração de $10 \mu \mathrm{g} \mathrm{mL}^{-1} \mathrm{em}$ diferentes períodos do dia (manhã, tarde e noite). A precisão intermediária foi determinada pela análise de seis medidas de soluções na mesma concentração realizadas em dias distintos.

\section{Exatidão}

Este parâmetro foi determinado através de adição do padrão, onde diferentes concentrações do padrão de aciclovir $(7,5 ; 12,5$ e 17,5 $\mu \mathrm{g}$ $\left.\mathrm{mL}^{-1}\right)$ foram adicionadas à solução amostra $(2,5 \mu \mathrm{g} \mathrm{mL}-1)$ estando a concentração final compreendida na linearidade e faixa do método.

\section{Robustez}

A robustez da metodologia proposta foi determinada por meio da análise de soluções amostras $\left(10 \mu \mathrm{g} \mathrm{mL}^{-1}\right)$ em diferentes comprimentos de onda (252, 254 e $256 \mathrm{~nm}$ ), diferentes valores de $\mathrm{pH}$ da solução (1,0; $1,2 ; 1,4)$ e diferentes concentrações de acido clorídrico $(0,05 ; 0,1 ; 0,2 \mathrm{~N})$.

\section{Dissolução}

Os comprimidos matriciais contendo ACV, designados $\mathrm{F} 1, \mathrm{~F} 2$, F3 e F4, foram submetidos ao ensaio de dissolução. Estes estudos foram realizados utilizando-se aparato II, o qual foi operado em uma velocidade de $50 \mathrm{rpm}$ em $900 \mathrm{~mL}$ de $\mathrm{HCl} \mathrm{0,1} \mathrm{N} \mathrm{(pH} \mathrm{1,2)} \mathrm{a} 37$ ${ }^{\circ} \mathrm{C}$, a quantidade de meio retirada em cada intervalo de tempo foi reposta. As amostras foram centrifugadas e analisadas usando-se um espectrofotômetro na região UV em $254 \mathrm{~nm}$.

\section{Análises estatísticas}

A análise estatística dos dados foi realizada através de análise de variância ANOVA unifatorial, onde os resultados são considerados significativos quando a probabilidade é inferior a $5 \%$ ( $\mathrm{p}<0,05$ intervalo de confiança de 95\%), teste t de Student com nível de significância $\alpha=0,05$ (intervalo de confiança de $95 \%$ ). A avaliação estatística dos resultados foi realizada através do Software ORIGIN 70 e MS Excel ${ }^{\circledR}$.

\section{RESULTADOS E DISCUSSÃO}

O processo de validação é essencial para definir se uma metodologia desenvolvida está completamente adequada aos objetivos a que se destina, a fim de se obter resultados confiáveis que possam ser satisfatoriamente interpretados. ${ }^{12}$

A especificidade é definida como a capacidade que o método possui de medir exatamente um composto em presença de outros componentes, tais como impurezas, produtos de degradação e componentes da matriz. ${ }^{12,17}$ Os espectros demonstraram que o método é específico, pois não ocorreu sobreposição dos picos de absorção do ACV com os demais constituintes da formulação no comprimento de onda utilizado para as análises (Figura 2).

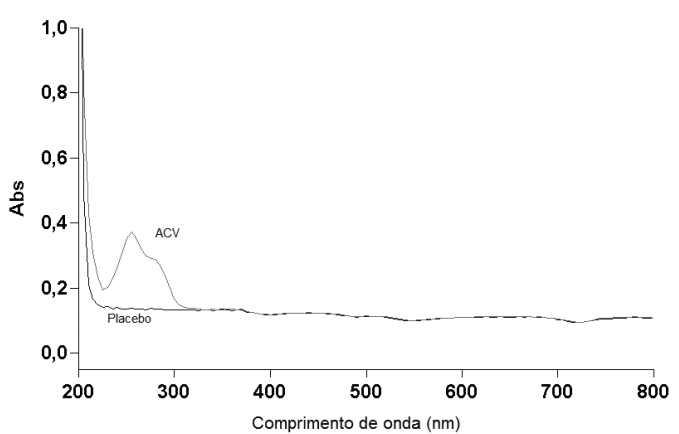

Figura 2. Espectro de absorção no ultravioleta do ACV $\left(10 \mu \mathrm{g} \mathrm{mL}^{-1}\right)$ e solução placebo em $\mathrm{HCl} 0,1 \mathrm{~N}$

A linearidade do método analítico foi avaliada através de análise de variância, verificando-se a regressão linear significativa e o desvio da linearidade não significativo $(\mathrm{p}<0,05)$ com análise de soluções com concentrações compreendidas entre 2,5 e $20 \mu \mathrm{g} \mathrm{mL} \mathrm{m}^{-1}$. O coeficiente de correlação encontrado para a curva média foi de 0,9999 (Tabela 1).

Tabela 1. Dados referentes à linearidade do método

\begin{tabular}{lc}
\hline Parâmetros & Resultados \\
\hline Faixa de linearidade & $2,5-20 \mu \mathrm{g} \mathrm{mL} \mathrm{L}^{-1}$ \\
Equação: $\mathrm{y}=\mathrm{ax}+\mathrm{b}$ & $\mathrm{y}=0,0557 \mathrm{x}+0,0096$ \\
Inclinação (b) \pm desvio padrão & $0,0096 \pm 0,0023$ \\
Inclinação (a) \pm desvio padrão & $0,5557 \pm 0,0031$ \\
Coeficiente de correlação (r) & 0,9999 \\
\hline
\end{tabular}

A sensibilidade do método foi avaliada pela determinação dos limites de quantificação (LQ) e de detecção (LD); os valores obtidos foram 0,76 e $0,26 \mu \mathrm{g} \mathrm{mL}^{-1}$, respectivamente, indicando boa sensibilidade do método. Durante o estabelecimento do perfil de liberação a quantidade de fármaco liberada varia desde valores extremamente baixos até valores mais elevados, quando ocorre a completa liberação do fármaco. Assim, valores de LQ baixos são de extrema importância, uma vez que as concentrações reduzidas serão detectadas e quantificadas com segurança.

Os resultados de repetibilidade e precisão intermediária foram expressos em termos de desvio padrão relativo (DPR) (Tabela 2). Neste 
ensaio foram utilizadas seis determinações e observada a diferença entre as repetições. A repetibilidade e precisão intermediária apresentaram DPR de 0,14 e $0,16 \%$, respectivamente. Os valores obtidos são inferiores a 2,0\%, limite máximo aceito para esse parâmetro. A análise de ANOVA demonstrou que não há diferenças estatísticas entre as análises dos diferentes períodos, F calculado foi de 1,022 e $\mathrm{F}$ de significação igual a 3,69 para $\mathrm{p}=0,05$.

Tabela 2. Resultados da repetibilidade (mesmo dia) e precisão intermediária (dias diferentes)

\begin{tabular}{lccc}
\hline $\begin{array}{l}\text { Solução amostra } \\
\left(10 \mu \mathrm{g} \mathrm{mL}^{-1}\right)\end{array}$ & $\begin{array}{c}\text { Absorbância } \pm \\
\text { D.P.R } \%\end{array}$ & $\begin{array}{c}\text { Solução amostra } \\
\left(10 \mu \mathrm{g} \mathrm{mL}^{-1}\right)\end{array}$ & $\begin{array}{c}\text { Absorbância } \pm \\
\text { D.P.R \% }\end{array}$ \\
\hline Manhã & $0,571 \pm 0,23$ & Dia 1 & $0,549 \pm 0,12$ \\
Tarde & $0,565 \pm 0,09$ & Dia 2 & $0,570 \pm 0,20$ \\
Noite & $0,546 \pm 0,11$ & Dia 3 & $0,555 \pm 0,18$ \\
Mesmo dia & $0,560 \pm 0,14$ & Dias diferentes & $0,558 \pm 0,16$ \\
\hline
\end{tabular}

*Média \pm D.P.R $(\mathrm{n}=6)$

A porcentagem média para a exatidão foi de $99,86 \pm 0,88 \%$, resultado que traduz o valor verdadeiro da amostra (Tabela 3). Através do teste $\mathrm{t}$ de Student, pode-se afirmar que o valor encontrado é estatisticamente igual a $100 \%$ para nível de significância $\alpha=0,05$.

Tabela 3. Recuperação do aciclovir adicionado à formulação analisada pelo método proposto

\begin{tabular}{lcccc}
\hline $\begin{array}{l}\text { Adição de padrão } \\
\text { de aciclovir } \\
(\mu \mathrm{g} / \mathrm{mL})\end{array}$ & $\begin{array}{c}\text { Concentração de } \\
\text { aciclovir final } \\
(\mu \mathrm{g} / \mathrm{mL})\end{array}$ & $\begin{array}{c}\text { Abs } \\
\text { média }\end{array}$ & $\begin{array}{c}\text { 土 DPR } \\
(\%)\end{array}$ & $\begin{array}{c}\text { Recuperação } \\
(\%)\end{array}$ \\
\hline 7,5 & 10 & 0,561 & 0,024 & 98,9 \\
12,5 & 15 & 0,851 & 0,036 & 100,7 \\
17,5 & 20 & 1,124 & 0,062 & 100,0 \\
\hline
\end{tabular}

*n = média de três determinações, Abs = absorbância, $\mathrm{DPR}=$ desvio padrão relativo.

Os dados experimentais obtidos para robustez, onde se avaliaram pequenas e deliberadas variações na metodologia analítica, indicaram que estas modificações não influenciaram significantemente os resultados $(F=3,89 ; \mathrm{F}$ de significação= 7,67; $\mathrm{p}=0,05)$ (Tabela 4).

Tabela 4. Dados relativos à robustez da metodologia proposta

\begin{tabular}{lccc}
\hline Parâmetros variados & $\begin{array}{c}\text { Absorbância da } \\
\text { solução amostra }\end{array}$ & $\begin{array}{c}\text { Concentração do } \\
\text { fármaco }(\%)\end{array}$ \\
\hline Comprimento de & 252 & 0,562 & 99,2 \\
onda (nm) & 254 & 0,559 & 98,6 \\
& 256 & 0,565 & 99,7 \\
pH da solução & 1,0 & 0,572 & 100,1 \\
& 1,2 & 0,558 & 98,5 \\
Concentração da & 1,4 & 0,564 & 99,5 \\
solução (N) & 0,05 & 0,562 & 99,2 \\
& 0,2 & 0,554 & 97,7 \\
\hline
\end{tabular}

Após a validação da metodologia analítica, procedeu-se à dissolução para demonstrar a aplicabilidade do método alternativo durante este ensaio. O perfil de liberação do ACV a partir das matrizes foi determinado por $24 \mathrm{~h}$ (Figura 3 ), sendo demonstrado nesse período que a totalidade do fármaco foi liberada.

\section{CONCLUSÃO}

A metodologia analítica por espectrofotometria na região do UV proposta para a quantificação do fármaco ACV em matrizes hidro-

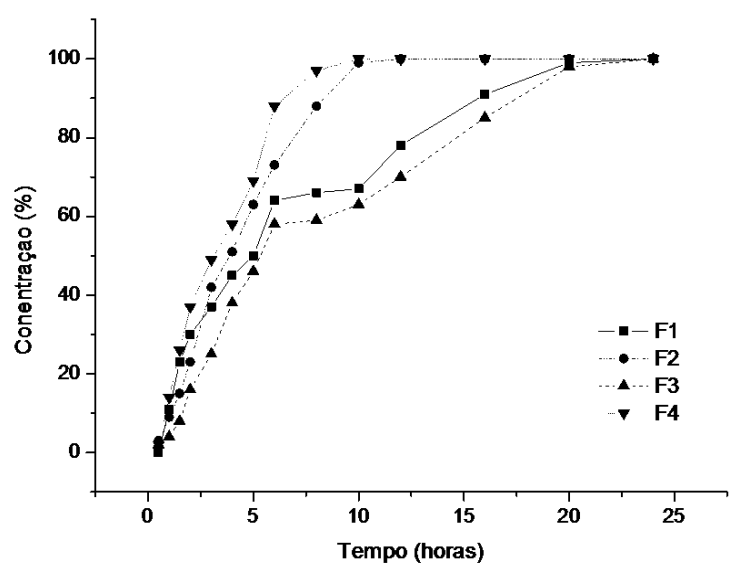

Figura 3. Perfil de liberação do ACV a partir das matrizes hidrofilicas em $\mathrm{HCl} 0,1 \mathrm{~N}$

fílicas demonstrou ser específica, linear, precisa, exata e robusta na faixa de 2,5 a $20 \mu \mathrm{g} \mathrm{mL}^{-1}$, sendo adequada para avaliação do fármaco em matrizes hidrofílicas. O método proposto também foi considerado aplicável aos testes de dissolução, uma vez que apresentou um limite de quantificação (LQ) de $0,76 \mu \mathrm{g} \mathrm{mL}^{-1}$, atendendo às exigências da formulação em estudo.

\section{REFERÊNCIAS}

1. Giammona, G.; Puglishi, G.; Cavallaro, G.; Spadaro, A.; Pitarresi, G.; J. Control. Release 1995, 33, 261.

2. Rossel, C. V.; Carrenõ, J. S.; Baeza, M. R.; Alderete, J. B.; Quim. Nova 2000, 23, 749.

3. Rang, H. P.; Dale, M. M.; Ritter, J. M.; Farmacologia. $4^{\mathrm{a}}$ ed., Ed. Guanabara Koogan: Rio de Janeiro, 2001.

4. Liesiene, J.; Matalioniene, J.; React. Funct. Polym. 2004, 59, 185.

5. Colombo, P.; Bettini, R.; Santi, P.; De Ascentiis, A.; Peppas, N. A.; J. Control. Release 1996, 39, 231.

6. Basavaiah, K.; Prameela, H. C.; Farmaco (Società Chimica Italiana: 1989) 2002, 57, 443.

7. Gandhi, P.; Momin, N.; Kharade, S.; Konapure, N. P.; Kuchekar, B. S.; Indian J. Pharm. Sci. 2006, 68, 516.

8. Basavaiah, K.; Prameela, H. C.; Chandrashekar, U.; Farmaco (Società Chimica Italiana: 1989) 2003, 58, 1301.

9. Jiageng, L. V.; Luo, L.; Zhanh, Z.; Anal. Chim. Acta 2004, 510, 35.

10. Huidobro, A. L.; Ruperez, F. J.; Barbas, C.; J. Pharm. Biomed. Anal. 2005, 37, 687 .

11. Neubert, R. H. H.; Mrestani, Y.; Schwarz, M.; Colin, B.; J. Pharm. Biomed. Anal. 1998, 16, 893.

12. The United States Pharmacopeia NF/25; Rockville: United States Pharmacopeial Convention, 2007.

13. Friedrich, R. B.; Ravanello, A.; Cichota, L. C.; Rolim, C. M. B.; Beck, R. C. R.; Quim. Nova 2009, 32, 1052.

14. Lachman, L.; Lieberman, H. A.; Kaning, J. L.; Teoria e Prática na Indústria Farmacêutica, Fundação Calouste: Lisboa, 2001.

15. Ansel, H. C.; Popovich, N. G.; Allen, L. V.; Formas Farmacêuticas e Sistemas de Liberação de Fármacos, Editorial Premier: São Paulo, 2000.

16. Agência Nacional de Vigilância Sanitária - ANVISA; RE nº 899, de 29/5/2003: Guia para validação de métodos analíticos e bioanalíticos, Ministério da Saúde: Brasil 2003.

17. ICH - International Conference on Harmonization of Technical Requeriments for registration of Pharmaceutical for Human use; $Q 2 B$ - validation of Analytical procedure: methodology, 1996. 